\title{
Different types of pancreatico-enteric anastomosis
}

\author{
Savio George Barreto ${ }^{1,2}$, Parul J. Shukla ${ }^{3}$ \\ ${ }^{1}$ Hepatobiliary and Oesophagogastric Unit, Division of Surgery and Perioperative Medicine, Flinders Medical Centre, Adelaide, Australia; ${ }^{2}$ College \\ of Medicine and Public Health, Flinders University, Bedford Park SA, Australia; ${ }^{3}$ Department of Surgery, Weill Cornell Medical College \& New \\ York Presbyterian Hospital, New York, USA \\ Contributions: (I) Conception and design: SG Barreto, PJ Shukla; (II) Administrative support: None; (III) Provision of study materials or patients: SG \\ Barreto; (IV) Collection and assembly of data: SG Barreto; (V) Data analysis and interpretation: SG Barreto; (VI) Manuscript writing: All authors; (VII) \\ Final approval of manuscript: All authors. \\ Correspondence to: Parul J. Shukla. Department of Surgery, Weill Cornell Medical College \& New York Presbyterian Hospital, New York, USA. \\ Email: pjshukla@hotmail.com.
}

\begin{abstract}
The pancreatico-enteric anastomosis has widely been regarded as the 'Achilles heel' of the modern day, single-stage, pancreatoduodenectomy (PD). A review of the literature was carried out to address the evolution of the pancreatico-enteric anastomosis following PD, the spectrum of anastomoses performed around the world, and finally present the current evidence in support of each anastomosis. Pancreaticogastrostomy (PG) and pancreaticojejunostomy (PJ) are the most common forms of pancreaticoenteric reconstruction following PD. There is no difference in postoperative pancreatic fistula (POPF) rates between PG and PJ, as well as individual variations, except in a high-risk anastomosis where performance of a PJ may be preferred. The routine use of glue, trans-anastomotic stents or omental wrapping is of no proven benefit. Externalised trans-anastomotic stents may have a role in mitigating the risk of a clinically relevant POPF in high-risk anastomoses. Pancreatico-enteric anastomosis is an important component of reconstruction following PD even though it is fraught with the risk of development of a POPF. Adherence to the tenets of anastomotic reconstruction and performance of a safe and reproducible anastomosis with a low clinically-relevant POPF rate remain the mainstay of achieving the best outcomes. Appropriate selection and opportune use of fistula mitigation strategies may help provide optimal outcomes when faced with the need to perform a high-risk pancreatico-enteric anastomosis.
\end{abstract}

Keywords: Pancreaticojejunostomy (PJ); pancreaticogastrostomy (PG); pancreatic fistula

Received: 21 August 2017; Accepted: 03 November 2017; Published: 14 November 2017.

doi: $10.21037 / \operatorname{tgh} .2017 .11 .02$

View this article at: http://dx.doi.org/10.21037/tgh.2017.11.02

\section{Introduction}

The pancreatico-enteric anastomosis has widely been regarded as the 'Achilles heel' of the modern day, singlestage, pancreatoduodenectomy (PD). Depending on the definition used, a leak from the anastomosis [postoperative pancreatic fistula (POPF)] has been reported to contribute to up to $45 \%$ of complications following PD (1). Over the years, considerable effort has gone into uncovering the factors that contribute to the poor outcome of a pancreatico-enteric anastomosis (soft pancreatic gland texture, small pancreatic duct at the level of anastomosis), as well as, developing scientifically-backed strategies to mitigate these factors (use of somatostatin analogues, transanastomotic stents, use of magnification) (2-6). Adherence to the basic principles of surgical reconstruction including performance of the anastomosis with care, using fine sutures, minimising the handling the pancreatic stump and bowel loop, ensuring a good blood supply (healthy and viable tissue being anastomosed), and absence of tension (4) or distal obstruction have been widely espoused. And while there has been a persistent drive, over the years, towards developing and improving the technique of pancreaticoenteric anastomosis, clinically-relevant POPF occurs 
in $11 \%$ of patients (7) and POPF-related mortality has continued to remain $1 \%$ over the last 25 years (8).

This review will provide an overview of the evolution of the pancreatico-enteric anastomosis following PD, the spectrum of anastomoses performed around the world, and finally present the current evidence in support of each anastomosis.

\section{The history of pancreatico-enteric anastomoses}

Codivilla performed the first en bloc excision of the head of the pancreas for pancreatic cancer (9). However, he did not perform a pancreatico-enteric anastomosis as part of the reconstruction. In fact, the first person to attempt a pancreatico-enteric anastomosis following a transduodenal partial PD was William Halsted (10). In 1898, he implanted the pancreatic duct into the repaired line of incision of the duodenum. He reported no POPF, an outcome that was also noted by other surgeons such as Koerte, Navarro, Kerr, Bohm, Schussler and Slaymer following transduodenal ampullary excision (11). However, for nearly 4 decades thereafter, surgeons in the United States performed pancreatic head resections without attempting to restore pancreatico-enteric continuity based on their philosophy that the activated enzyme-rich pancreatic juice entering the intestine was the cause for anastomotic failure. They also subscribed to the belief that the pancreatic capsule did not lend itself to an anastomosis or that the anastomosis would eventually get obstructed and patients could survive without pancreatic juice (5). Despite these perceptions, in Europe, Desjardins (in a human cadaver model) (12) and Coffey (in the canine model) (13) continued their experimental work in the early $20^{\text {th }}$ century attempting to ascertain the best method to restore pancreatico-enteric continuity. In 1912, Walter Kausch (14) described his two-staged PD for an ampullary cancer on a 49-year-old man with obstructive jaundice in which he fashioned a pancreaticoenteric anastomosis by suturing the transected end of the duodenum over the pancreatic stump. The patient succumbed in 9 months due to an ongoing bile leak and cholangitis from the unaddressed cut end of the common bile duct. Similar procedures were performed by Tenani in 1922 (11) and Nemenyi in 1935 (15).

By 1941, Allen Whipple began to appreciate that two important contributors to PD-related morbidity were pancreatic fistulae from the oversewed ducts, in the short-term, and fat indigestion necessitating pancreatic extracts in the long-term (16). By 1945, he reported the success of his single-staged procedure with the 'implantation' of the pancreatic duct into the jejunum below the choledochojejunostomy (17). Whipple believed this would obviate the development of the hitherto reported fatty liver degeneration because of pancreatic occlusion. However, Whipple was not the first American surgeon to successfully restore pancreatico-enteric continuity following a PD. History bears witness to the fact that Verne Hunt, from California, performed a total duodenectomy and cautery excision of part of the head of the pancreas, for an adenocarcinoma of the papilla of Vater, and successfully reconstructed the duct of Wirsung by a pancreaticojejunostomy $(\mathrm{PJ})$ on the $5^{\text {th }}$ of March 1941 at St. Vincent's hospital (11). Zinninger, too, reported performing a PJ at about the same time (18). Cattell (19), on the other hand, remained undecided about the whether to oversew the cut end of the pancreas, or anastomose it to the jejunum. He suggested combining a 'necrosing suture' ligation of the main pancreatic duct in the event of a small pancreatic duct and then suturing the jejunum around the cut surface of the pancreas. Varco advised suturing the pancreatic duct (implanting) into the jejunal wall using a two-hole catheter (20).

Following the initial mixed reports of experimental implantation of the pancreatic duct into the duodenum and jejunum as well as the high mortality rate accompanying 'blow outs' that accompanied merely oversewing the pancreatic duct (the most common practice prior to 1940), Tripodi and Sherwin performed the first experiments in dogs attempting what we now recognise as a pancreaticogastrostomy or PG (21). Person and Glenn (22) and Wells and Annis (23) also pursued this line of investigation in canine models owing to the clinical concerns of PJ anastomotic leaks. They believed that the $\mathrm{pH}$ and enterokinase in the jejunum, were key to converting trypsinogen into trypsin resulting in the digestion of the anastomosis. Ironically, the outcomes of experimental PG were not that impressive either. Some of the most elaborate and exhaustive work on experimental PG in the canine model was performed by Ferguson and Wangensteen comparing outcomes following direct suture anastomosis, as well as over stents, of the pancreatic duct to the duodenum, jejunum and stomach (24). Kauer and Glenn took on board findings from the canine model work on PG as well as reports of clinical outcomes by Whipple. They predicted that the ideal operation for pancreatic cancer would require, amongst other aspects, restoration of pancreatico-enteric continuity by transplanting the remnant pancreas into the 
Table 1 Types and techniques of Pancreatico-enteric anastomoses

\begin{tabular}{|c|c|c|c|c|}
\hline Type of anastomosis & Surface involved in anastomosis & Technique of anastomosis & Technique first described by & Reference \\
\hline \multirow{3}{*}{ PJ } & & Invagination/dunking & Aston \& Longmire & (30) \\
\hline & End-to-side & Invaginating & Aston \& Longmire & (30) \\
\hline & & Duct-to-mucosa & Whipple AO & (31) \\
\hline \multirow{3}{*}{ PG } & & Invaginating/telescoping & Wells et al. & (32) \\
\hline & & & Mackie et al. & (33) \\
\hline & & Duct-to-mucosa & Telford \& Mason & (34) \\
\hline
\end{tabular}

PJ, Pancreatojejunostomy; PG, pancreaticogastrostomy.

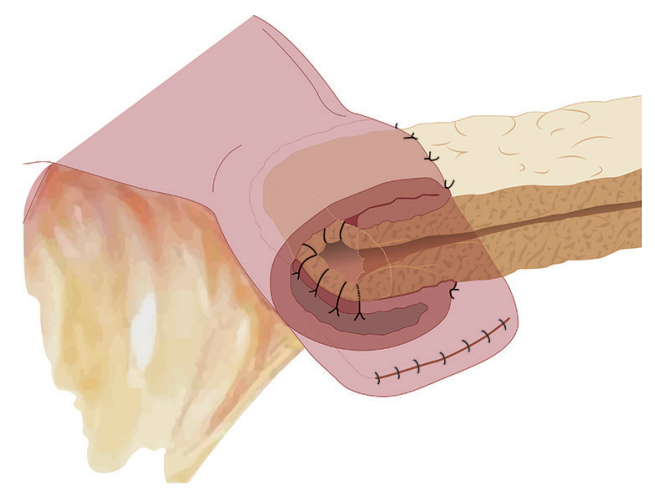

Figure 1 Diagrammatic representation of the invaginating end-toside pancreaticojejunostomy.

posterior wall of the stomach (25). The first to successfully perform a PG were Waugh and Clagett (26) in a cohort of 30 patients (26). The rationale provided for PG being an improved alternative to $\mathrm{PJ}$ include the suggestion that the anastomosis is tension-free (since the body of the pancreas forms the bed of the stomach and the weight of biliary and pancreatic secretions pooling up in the jejunum exerting a traction effect on the anastomosis is obviated), well vascularized (considering the robust gastric blood supply), without risk of activation of pancreatic enzymes or mixing of the pancreatic and biliary secretions $(27,28)$.

This initial body of experimental and clinical work led to an appreciation of the importance of restoring the flow of pancreatic juice into the gastrointestinal tract to enable fat, carbohydrate and protein digestion. Thus, the pancreaticoenteric anastomosis (PJ or PG) became an established component of reconstruction following PD. Thereafter, what followed was essentially a series of attempts by surgeons to introduce minor modifications in PJ/PG with an aim to improve the safety of the anastomosis by reducing the pancreatic fistula rate of $19.5 \%$ and a mortality rate of $29.2 \%$ associated with PD (16).

\section{Types of pancreatico-enteric anastomosis}

Table 1 provides a broad overview of the various types of pancreatico-enteric anastomosis (26,29-34). Fingerhut and colleagues have advised that the appropriate nomenclature when describing pancreatico-enteric anastomosis should be such that if the duct is joined to the mucosa of the bowel, then the anastomosis should preferably be referred to as pancreatico-enteric. Alternatively, if ductal sutures are not included, then the term pancreato-enteric anastomosis is sufficient (35).

The duct-to-mucosa PJ has certainly evolved over the decades from the initial reports $(31,36)$ wherein the duct was anastomosed to the jejunum over a tube with the rest of the pancreas parenchyma sutured off/oversewed with mattress sutures, to the current two concentric layered anastomosis including the rest of the pancreatic parenchyma in the anastomosis without the need for duct intubation described by Blumgart $(37,38)$. The end-to-side $\mathrm{PJ}$ is generally performed as a four-layered anastomosis approximating pancreatic capsule and parenchyma to the seromuscular layer of the jejunum in the first and fourth layers and duct to mucosa in the middle two layers (39). The only major difference in the inversion or invaginating end-to-side anastomosis (Figure 1) and the duct-tomucosa end-to-side anastomosis is in the size of the jejunal opening - a wide jejunal opening matching the diameter of the cut surface of the pancreas in the former and a 


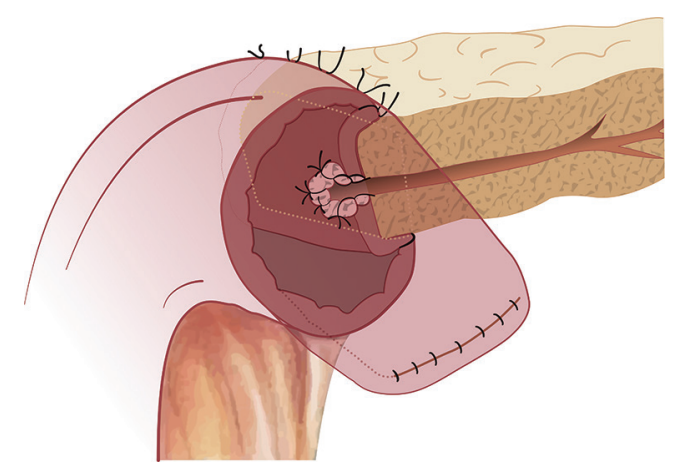

Figure 2 Diagrammatic representation of the duct-to-mucosa pancreaticojejunostomy.

'pin-hole' opening in the jejunum in the latter (Figure 2). The authors have successfully resorted to the use of an interrupted end-to-side invaginating PJ using just the two outer layers in high risk anastomoses (soft texture with a small unidentifiable duct in which placement of ductal sutures is not feasible) $(40,41)$.

\section{Variations in the performance of $P \mathcal{F}$ and $P G$}

Numerous variations to both, the PJ and PG, have been described largely because the ideal anastomotic technique for a soft/fatty or even brittle pancreas with a small duct $(<3 \mathrm{~mm})$ remains elusive. Shinchi and colleagues (42) described the use of a single layer of transfixing sutures between the pancreatic remnant and the posterior gastric wall to reinforce the duct-to-mucosa PG. Shuyou Peng described his 'binding' PJ technique in 2002 to help overcome the problems of a soft pancreas (43). The technique involved several specific steps, namely, isolating the pancreatic remnant for $3 \mathrm{~cm}$, everting and ablating (electro-coagulation or chemical) the distal $3 \mathrm{~cm}$ of the exposed mucosa of the cut end of jejunum, suturing the pancreas to the jejunal mucosa (avoiding the seromuscular layer) with intermittent or continuous silk, wrapping the pancreatic stump with the everted jejunum and securing it in place with a few sutures, and finally looping a catgut tie $1 \mathrm{~cm}$ from the cut end of jejunum. The anastomosis is then tested to ensure watertight closure. While Peng initially reported a $0 \%$ POPF rate from 150 patients in whom he performed the 'binding' PJ (44), by 2011, he himself reported that the technique was fraught with two risks, namely, a size discrepancy between pancreas stump and jejunum, and the risk of the pancreatic fixation sutures leading to exudation of pancreatic juice into the abdominal cavity. Thus prompting him to propose his 'binding' PG (45) which involved isolating the pancreatic stump for $2 \mathrm{~cm}$, excising a piece of seromuscular layer of the posterior gastric wall (the size being equivalent to pancreatic stump and the location corresponding to it, as well,) with a preplaced purse-string seromuscular suture, and the pancreatic stump is then invaginated through a small incision in the mucosal layer. Using an anterior gastrotomy, the edge of the mucosal opening at the posterior gastric wall is held up by forceps forming a mucosal tube, around which the second purse-string suture is pre-placed. Finally, the two purse-string sutures are tied around the pancreas that is drawn into the gastric lumen.

Fernandez-Cruz and colleagues (46) proposed the construction of an end-to-side, duct-to-mucosa anastomosis (with an internal pancreatic duct silastic stent) of the transected pancreas to a tube of stomach they termed 'gastric partition' following a pylorus-preserving PD. The 'Gastric partition' is carried out using two endo-GIA staplers along the greater curvature of the stomach, $3 \mathrm{~cm}$ from the border after preserving the gastroepiploic arcade. The resultant gastric segment of 10 to $12 \mathrm{~cm}$ length is placed in close proximity to the cut edge of the pancreatic stump to facilitate the anastomosis. The duodeno-jejunostomy and hepaticojejunostomy are then constructed downstream.

To facilitate the performance of a duct-to-mucosa PJ even in patients with small pancreatic ducts, the authors have previously proposed the use of the 'duct evagination' technique (47) which involves the placement of interrupted 5-0 suture ties around the entire circumference of the pancreatic duct.

Zhang and colleagues have described their 'papillarylike main pancreatic duct invagination' technique (48) in which 1 to $1.2 \mathrm{~cm}$ of the pancreatic duct is isolated from the surrounding parenchyma is moulded into a 'fish mouthlike' shape with the pancreatic duct protruding out of the stump. The pancreatic stump (excluding the protruding duct) is then closed with interrupted inverting sutures. The anastomosis thereafter essentially proceeds like a duct-tomucosa four layered anastomosis with the duct invaginating into the jejunum.

Another variation to $\mathrm{PJ}$ is the performance of the anastomosis of the pancreas to an isolated Roux limb of jejunum (49) with an aim to divert the biliary secretions away from the PJ and ensure that even if a POPF does develop after the anastomosis, the effluent from the leak will consist of 'pure', unactivated, and thus harmless pancreatic juice (50). 


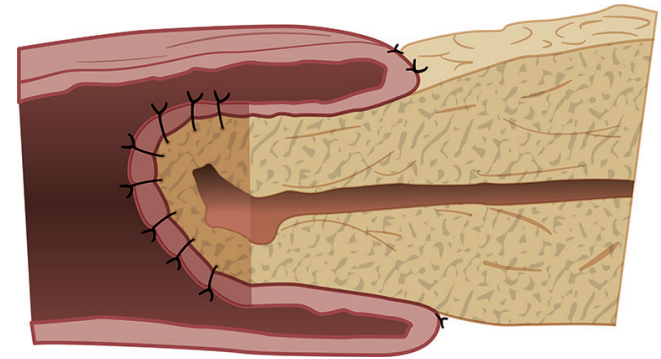

Figure 3 Diagrammatic representation of the end-to-end dunking/ invaginating pancreaticojejunostomy.

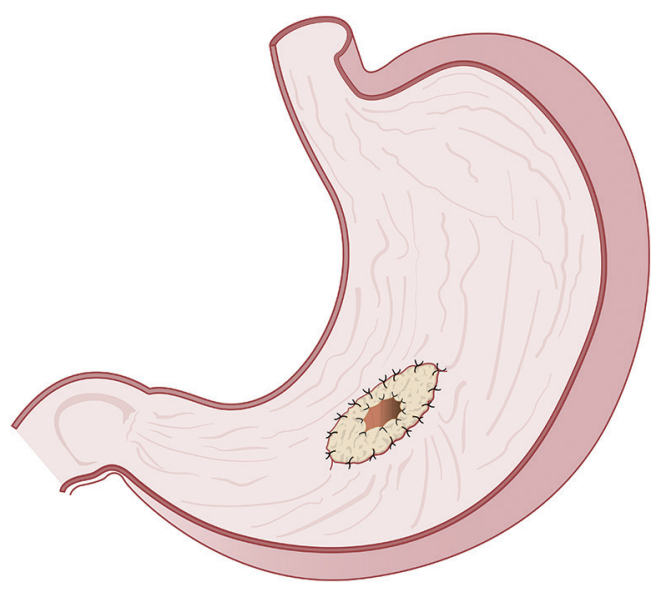

Figure 4 Diagrammatic representation of the duct-to-mucosa pancreaticogastrostomy.

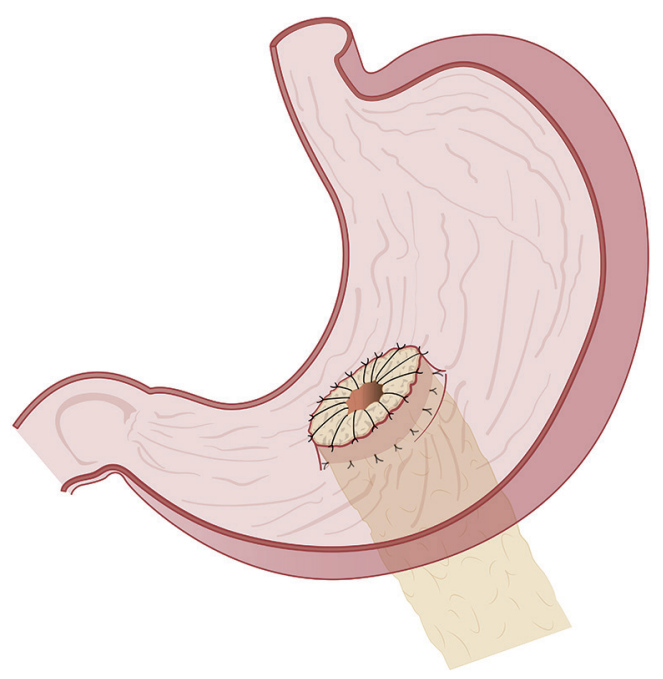

Figure 5 Diagrammatic representation of the invaginating end-toside pancreaticogastrostomy.

\section{Anastomosis over stents}

Anastomosing the pancreatic duct to the jejunum or stomach was performed over an internal (rubber tube) stent by Whipple (31) and Wells (32). Thereafter, surgeons attempted to perform the anastomoses over stents that were exteriorised (controlled fistula) (2,51). Today, most surgeons would perform an anastomosis without a stent, although, the use of stents is not uncommon. Some surgeons have even attempted, rather unsuccessfully, to develop biodegradable internal stents (52).

\section{Use of supporting/reinforcing material}

Tashiro and colleagues (53) proposed the use of a fibrin glue biological adhesive as a reinforcing layer to the PJ in order to reduce the risk of POPF. Moriura and colleagues (54) instead suggested that wrapping the PJ as well as the retroperitoneal vessels had the potential to reduce the incidence of POPF as well prevent haemorrhage from the vessels in case the anastomosis did leak.

The most commonly performed pancreatico-enteric anastomosis around the world is the PJ (88.7\%) followed by the PG (9.7\%) (55). The most commonly performed variations of the two-main anastomoses include the duct-tomucosa, end-to-side PJ, followed by the invaginating endto-side or end-to-end (Figure 3) PJ, and the invaginating or duct-to-mucosa, end-to-side PG (Figures 4,5). The use of stents, as well as, reinforcements is highly variable (55).

The effect of the type of suture material (absorbable versus non-absorbable) used to perform the pancreaticoenteric anastomosis, as well as, the technique of suturing has also been analysed with respect to the development of POPF. Suture material induces changes in the pancreas akin to acute pancreatitis thus supporting the rationale for thinner, and fewer, sutures (56). While there exists significant variability in the type of material used amongst surgeon around the world (55), an absorbable monofilament (e.g., polydioxanone, Maxon, Monocryl) is favoured for the inner layer of a duct-to-mucosa anastomosis, while the nonabsorbable braided (e.g., silk, polyester) and absorbable monofilament sutures are equally favoured for the outer layer of the anastomosis. There is evidence from a single study to suggest a lower severity of POPF with the use of non-absorbable sutures versus absorbable sutures (57). In fact, polyester resulted in a significantly lower POPF rate 
compared to polydioxanone ( $12 \%$ vs. $32 \%$; $\mathrm{P}<0.01)(57)$. Studies comparing the performance of a continuous versus an interrupted suture anastomosis favour the use of the continuous technique for PJ $(58,59)$.

\section{Results}

While the surgical fraternity are all agreed that restoration of the flow of pancreatic juice into the intestine is an important component of the reconstruction following a PD, the choice of location of the anastomosis, as well as, the technique has been the focus of research and surgical debate over the last few decades.

\section{$P G$ vs. Pf}

The most updated meta-analysis (60) comparing PJ versus PG that included 10 randomised controlled trials (RCTs) and 1,629 patients concluded that while there was no difference in the two anastomotic techniques in terms of biliary fistula, morbidity, and mortality, PG was associated with a significantly lower risk of POPF (OR: 0.72; $\mathrm{P}<0.009)$. Interestingly, when Crippa and colleagues (61) analysed the same data taking into consideration the significant heterogeneity in the included studies in terms of the definitions of POPF, perioperative management, and characteristics of pancreatic gland there was no significant difference in the rate of overall and clinically significant POPF, morbidity, mortality, reoperation, and intraabdominal sepsis when PG was compared with all types PJ. Comparison of the various technical modifications between the two anastomotic techniques failed to demonstrate a significant difference in outcomes.

A multinational analysis has revealed that $P G$ is associated with a significantly higher clinically-relevant POPF rate as compared to PJ (62) in anastomoses regarded as high-risk by the Fistula Risk Score (FRS) (63). The use of mitigation strategies such as selective prophylactic drainage, and the omission of octreotide and internal stents, however, may help reduce the risks associated with the performance of a PG (64).

\section{Variations in P7}

In another recent meta-analysis (65) comparing the results of 8 RCTs and 850 patients who underwent the duct-tomucosa or invagination technique of $\mathrm{PJ}$, no significant difference in POPF, morbidity, mortality or reoperation rate was noted. Patients undergoing the duct-to-mucosa PJ had a significantly shorter postoperative hospital stay $(\mathrm{P}<0.02)$.

There is no significant difference in POPF rates between the binding technique of $\mathrm{PJ}$ as compared to other variations of $\mathrm{PJ}(66)$.

\section{Roux limb PY}

A meta-analysis that included 3 RCTs and 4 controlled clinical trials (total of 802 patients) compared the standard single loop reconstruction versus the dual-loop (Roux-en-Y) PJ (67). Performance of the PJ to an isolated Roux limb did not show any superiority to the standard reconstruction in terms of POPF, delayed gastric emptying, haemorrhage, overall morbidity, mortality, reinterventions, reoperations, and length of hospital stay.

\section{Pancreatico-enteric anastomoses over stents}

The role of stents across pancreatico-enteric anastomoses has been well studied in a recent Cochrane review (68). The quality of evidence comparing the use of stents versus no stent in terms of development of POPF was low, precluding the derivation of any valid conclusions. The same set of problems have plagued the evidence comparing the use of internal versus external stents. Moreover, the use of internal stents is fraught with the risk of migration in up to $17 \%$ of patients (8).

Albeit, while the routine use of externalised stents across the pancreatico-enteric anastomosis is not supported in literature (69), there is some evidence that their use in highrisk patients (FRS 7-10) may lead to a significantly reduced rate of clinically relevant POPF (70).

\section{Fibrin glue}

Based on the findings of the only RCT (71) that filed to find a benefit for the use of glue in preventing POPF, a review of the literature (72) concluded that the evidence to support the use of glue to seal even a high-risk anastomosis was lacking. A more recent Cochrane review has confirmed that fibrin sealants do not prevent POPF (73).

\section{Omental wrapping of the pancreatico-enteric anastomosis}

Based on a systematic review of the low level of evidence in literature that included 12 studies, Ramia and colleagues (74) indicated that there was no justification for routine omental 
wrapping of the pancreatico-enteric anastomosis and vessels.

\section{Discussion}

These data support the need for routine performance of pancreatico-enteric anastomosis following PD. However, there is no conclusive evidence in literature that any technique is better than the other (7) except in the setting of a high-risk anastomosis (by FRS score) wherein a PJ would be preferred to a PG (62). There is no evidence to support the routine use of stents, fibrin glue or omental wrapping.

Given the lack of superiority of one technique over the other, it is imperative that surgeons adopt a well-established method of anastomosis and espouse the basic principles of surgical reconstruction. The impact of standardising one's technique of anastomosis to achieve improved outcomes (39) has been previously demonstrated. The ability to reach the stage of standardisation rests on a surgeon's ability to critically audit his/her own outcomes at regular intervals and introduce changes that would enable the performance of a safe and reproducible anastomosis with a low clinicallyrelevant POPF rate $[<11 \%(75)]$. The repeated performance of the same technique of anastomosis that leads to an unacceptably high POPF rate is not standardisation, but surgical hubris at its worst! Pancreatic surgeons should also familiarise themselves with the various fistula mitigating strategies and the evidence to back their use. Such knowledge is likely to prove useful when faced with a difficult to manage pancreatic stump requiring reconstruction (62).

The pursuit of perfection and achieving a 'zero percent' POPF rate remains a dream of every pancreatic surgeon. While the evidence remains equivocal in terms of outcomes across the board, in high-risk anastomoses, the use of externalised stents has been shown to mitigate the risk (62) of development of clinically relevant POPF (1).

\section{Conclusions}

Pancreatico-enteric anastomosis is an important component of reconstruction following PD even though it is fraught with the risk of development of a POPF. There is no difference in POPF rates between PG and PJ, as well as individual variations, except in a high-risk anastomosis where performance of a PJ may be preferred. The routine use of glue, trans-anastomotic stents or omental wrapping is of no proven benefit. Externalised trans-anastomotic stents may have a role in mitigating the risk of a clinically relevant POPF in high-risk anastomoses. Adherence to the tenets of anastomotic reconstruction and performance of a safe and reproducible anastomosis with a low clinicallyrelevant POPF rate remain the mainstay of achieving the best outcomes. Appropriate selection and opportune use of fistula mitigation strategies may help provide optimal outcomes when faced with the need to perform a high-risk pancreatico-enteric anastomosis.

\section{Acknowledgements}

The authors acknowledge the work of Eric Lum on the illustrations in the manuscript.

\section{Footnote}

Conflicts of Interest: The authors have no conflicts of interest to declare.

\section{References}

1. Bassi C, Marchegiani G, Dervenis C, et al. The 2016 update of the International Study Group (ISGPS) definition and grading of postoperative pancreatic fistula: 11 Years After. Surgery 2017;161:584-91.

2. Shukla PJ, Barreto SG, Fingerhut A. Do transanastomotic pancreatic ductal stents after pancreatic resections improve outcomes? Pancreas 2010;39:561-6.

3. Shukla PJ, Barreto SG, Fingerhut A, et al. Toward improving uniformity and standardization in the reporting of pancreatic anastomoses: a new classification system by the International Study Group of Pancreatic Surgery (ISGPS). Surgery 2010;147:144-53.

4. Shrikhande SV, Qureshi SS, Rajneesh N, et al. Pancreatic anastomoses after pancreaticoduodenectomy: do we need further studies? World J Surg 2005;29:1642-9.

5. Kakita A, Yoshida M, Takahashi T. History of pancreaticojejunostomy in pancreaticoduodenectomy: development of a more reliable anastomosis technique. J Hepatobiliary Pancreat Surg 2001;8:230-7.

6. Wada K, Traverso LW. Pancreatic anastomotic leak after the Whipple procedure is reduced using the surgical microscope. Surgery 2006;139:735-42.

7. Shrikhande SV, Sivasanker M, Vollmer CM, et al. Pancreatic anastomosis after pancreatoduodenectomy: A position statement by the International Study Group of Pancreatic Surgery (ISGPS). Surgery 2017;161:1221-34. 
8. Pedrazzoli S. Pancreatoduodenectomy (PD) and postoperative pancreatic fistula (POPF): A systematic review and analysis of the POPF-related mortality rate in 60,739 patients retrieved from the English literature published between 1990 and 2015. Medicine (Baltimore) 2017;96:e6858.

9. Shukla PJ, Barreto G, Shrikhande SV. The evolution of pancreatoduodenectomy. Hepatogastroenterology 2011;58:1409-12.

10. Halsted $W$. Contribution to the surgery of the bile passages, especially of the common bile-duct. Boston Med Surg J 1899;41:645-54.

11. Hunt VC. Surgical Management of Carcinoma of the Ampulla of Vater and of the Periampullary Portion of the Duodenum. Ann Surg 1941;114:570-602.

12. Desjardins A. Technique de la pancreatectomie. Rev Chir Paris 1907;35:945.

13. Coffey RC. XVII. Pancreato-enterostomy and Pancreatectomy: A Preliminary Report. Ann Surg 1909;50:1238-64.

14. Kausch W. Das carcinom der papilla duodeni und seine radikale entfernung. Beitr Klin Chir 1912;78:471-624.

15. Nemenyi G. Zur operationstechnik des Papillen karzinoms. Zentralbl f Chir 1937;64:1337-9.

16. Whipple AO. The Rationale of Radical Surgery for Cancer of the Pancreas and Ampullary Region. Ann Surg 1941;114:612-5.

17. Whipple AO. Pancreaticoduodenectomy for Islet Carcinoma: A Five-Year Follow-Up. Ann Surg 1945;121:847-52.

18. Zinninger $M$. Radical resection of duodenum and head of pancreas for carcinoma of ampulla of Vater. Repair of pancreatic fistula using vitallium tube. Cincinnati J Med 1941;23:174-6.

19. Cattell R. Resection of the pancreas, discussion of special problems. Surg Clin North Am 1943;23:753-66.

20. Varco RL. A method of implanting the pancreatic duct into the jejunum in the Whipple operation for carcinoma of the pancreas. Surgery 1945;18:569-73.

21. Tripodi A, Sherwin C. Experimental transplantation of the pancreas into the stomach. Arch Surg 1934;28:345.

22. Person E, Glenn F. Pancreaticogastrostomy: Experimental transplantation of the pancreas into the stomach. Arch Surg 1939;39:530.

23. Wells CA, Annis D. Experimental pancreaticogastrostomy. Lancet 1949;1:97-9.

24. Ferguson DJ, Wangensteen OH. Experimental anastomoses of the pancreatic duct. Ann Surg
1950;132:1066-74.

25. Kauer J, Glenn F. Carcinoma of the Pancreas. Arch Surg $1941 ; 42$.

26. Waugh JM, Clagett OT. Resection of the duodenum and head of the pancreas for carcinoma; an analysis of thirty cases. Surgery 1946;20:224-32.

27. Icard P, Dubois F. Pancreaticogastrostomy following pancreatoduodenectomy. Ann Surg 1988;207:253-6.

28. Sikora SS, Posner MC. Management of the pancreatic stump following pancreaticoduodenectomy. Br J Surg 1995;82:1590-7.

29. Child CG. Carcinoma of the Duodenum. Ann Surg 1943;118:838-42.

30. Aston SJ, Longmire WP Jr. Management of the pancreas after pancreaticoduodenectomy. Ann Surg 1974;179:322-7.

31. Whipple A. Observations on radical surgery for lesions of the pancreas. Surg Gynecol Obstet 1946;82:623-31.

32. Wells C, Shepherd JA, Gibbon N. Pancreaticogastrostomy. Lancet 1952;1:588-9.

33. Mackie JA, Rhoads JE, Park CD. Pancreaticogastrostomy: a further evaluation. Ann Surg 1975;181:541-5.

34. Telford GL, Mason GR. Pancreaticogastrostomy: clinical experience with a direct pancreatic-duct-to-gastric-mucosa anastomosis. Am J Surg 1984;147:832-7.

35. Fingerhut A, Vassiliu P, Dervenis C, et al. What is in a word: Pancreatoduodenectomy or pancreaticoduodenectomy? Surgery 2007;142:428-9.

36. Cattell R. A technique for pancreaticoduodenal resection. Surg Clin North Am 1948;28:761-75.

37. Blumgart L, Fong F. Surgery of the liver and biliary tract. 3rd edition. New York: Saunders Co. Ltd., 2000.

38. Grobmyer SR, Kooby D, Blumgart LH, et al. Novel pancreaticojejunostomy with a low rate of anastomotic failure-related complications. J Am Coll Surg 2010;210:54-9.

39. Shrikhande SV, Barreto G, Shukla PJ. Pancreatic fistula after pancreaticoduodenectomy: the impact of a standardized technique of pancreaticojejunostomy. Langenbecks Arch Surg 2008;393:87-91.

40. Chaudhary A, Barreto S, Talole S, et al. Early discharge after Pancreatoduodenectomy - what helps and what prevents? Pancreas 2015;44:273-8.

41. Barreto SG, Singh A, Perwaiz A, et al. Maximum surgical blood order schedule for pancreatoduodenectomy: a long way from uniform applicability! Future Oncol 2017;13:799-807.

42. Shinchi H, Takao S, Maemura K, et al. A new technique for pancreaticogastrostomy for the soft pancreas: the 
transfixing suture method. J Hepatobiliary Pancreat Surg 2006;13:212-7.

43. Peng S, Mou Y, Cai X, et al. Binding pancreaticojejunostomy is a new technique to minimize leakage. Am J Surg 2002;183:283-5.

44. Peng SY, Mou YP, Liu YB, et al. Binding pancreaticojejunostomy: 150 consecutive cases without leakage. J Gastrointest Surg 2003;7:898-900.

45. Peng SY, Wang JW, Hong DF, et al. Binding pancreaticoenteric anastomosis: from binding pancreaticojejunostomy to binding pancreaticogastrostomy. Updates Surg 2011;63:69-74.

46. Fernandez-Cruz L, Cosa R, Blanco L, et al. Pancreaticogastrostomy with gastric partition after pylorus-preserving pancreatoduodenectomy versus conventional pancreatojejunostomy: a prospective randomized study. Ann Surg 2008;248:930-8.

47. Shukla PJ, Sakpal SV, Barreto SG, et al. Pancreato-enteric anastomosis: the duct evagination technique. J Surg Oncol 2009; 100:277-8.

48. Zhang B, Xu J, Liu C, et al. Application of "papillary-like main pancreatic duct invaginated" pancreaticojejunostomy for normal soft pancreas cases. Sci Rep 2013;3:2068.

49. Machado MC, da Cunha JE, Bacchella T, et al. A modified technique for the reconstruction of the alimentary tract after pancreatoduodenectomy. Surg Gynecol Obstet 1976;143:271-2.

50. Perwaiz A, Singhal D, Singh A, et al. Is isolated Roux loop pancreaticojejunostomy superior to conventional reconstruction in pancreaticoduodenectomy? $\mathrm{HPB}$ (Oxford) 2009;11:326-31.

51. Smith R. Progress in the surgical treatment of pancreatic disease. Am J Surg 1973;125:143-53.

52. Nordback I, Lamsa T, Laukkarinen J, et al. Pancreaticojejunostomy with a biodegradable pancreatic stent and without stitches through the pancreas. Hepatogastroenterology 2008;5 5:319-22.

53. Tashiro S, Murata E, Hiraoka T, et al. New technique for pancreaticojejunostomy using a biological adhesive. Br J Surg 1987;74:392-4.

54. Moriura S, Ikeda S, Ikezawa T, et al. The inclusion of an omental flap in pancreatoduodenectomy. Surg Today 1994;24:940-1.

55. McMillan MT, Malleo G, Bassi C, et al. Defining the practice of pancreatoduodenectomy around the world. HPB (Oxford) 2015;17:1145-54.

56. Lamsa T, Jin HT, Nordback PH, et al. Effects of diameter, number and tightness of sutures on pancreatic injury response. Dig Surg 2008;25:269-77.

57. Andrianello S, Pea A, Pulvirenti A, et al.

Pancreaticojejunostomy after pancreaticoduodenectomy:

Suture material and incidence of post-operative pancreatic fistula. Pancreatology 2016;16:138-41.

58. Ji W, Shao Z, Zheng K, et al. Pancreaticojejunostomy with double-layer continuous suturing is associated with a lower risk of pancreatic fistula after pancreaticoduodenectomy: a comparative study. Int J Surg 2015;13:84-9.

59. Chen Y, Ke N, Tan C, et al. Continuous versus interrupted suture techniques of pancreaticojejunostomy after pancreaticoduodenectomy. J Surg Res 2015;193:590-7.

60. Qin H, Luo L, Zhu Z, et al. Pancreaticogastrostomy has advantages over pancreaticojejunostomy on pancreatic fistula after pancreaticoduodenectomy. A meta-analysis of randomized controlled trials. Int J Surg 2016;36:18-24.

61. Crippa S, Cirocchi R, Randolph J, et al. Pancreaticojejunostomy is comparable to pancreaticogastrostomy after pancreaticoduodenectomy: an updated meta-analysis of randomized controlled trials. Langenbecks Arch Surg 2016;401:427-37.

62. Ecker BL, McMillan MT, Asbun HJ, et al. Characterization and Optimal Management of High-Risk Pancreatic Anastomoses During Pancreatoduodenectomy. Ann Surg 2017. [Epub ahead of print].

63. Callery MP, Pratt WB, Kent TS, et al. A prospectively validated clinical risk score accurately predicts pancreatic fistula after pancreatoduodenectomy. J Am Coll Surg 2013;216:1-14.

64. Ecker BL, McMillan MT, Maggino L, et al. Pancreatogastrostomy Vs. Pancreatojejunostomy: a RiskStratified Analysis of 5316 Pancreatoduodenectomies. J Gastrointest Surg 2017. [Epub ahead of print].

65. Sun X, Zhang Q, Zhang J, et al. Meta-analysis of invagination and duct-to-mucosa pancreaticojejunostomy after pancreaticoduodenectomy: An update. Int J Surg 2016;36:240-7.

66. Zhang X, Dong X, Liu P, et al. Binding versus Conventional Pancreaticojejunostomy in Preventing Postoperative Pancreatic Fistula: A Systematic Review and Meta-Analysis. Dig Surg 2017;34:265-80.

67. Klaiber U, Probst P, Knebel P, et al. Meta-analysis of complication rates for single-loop versus dual-loop (Rouxen-Y) with isolated pancreaticojejunostomy reconstruction after pancreaticoduodenectomy. Br J Surg 2015;102:331-40.

68. Dong Z, Xu J, Wang Z, et al. Stents for the prevention of pancreatic fistula following pancreaticoduodenectomy. Cochrane Database Syst Rev 2016:CD008914. 
69. Sachs TE, Pratt WB, Kent TS, et al. The pancreaticojejunal anastomotic stent: friend or foe? Surgery 2013;153:651-62.

70. McMillan MT, Ecker BL, Behrman SW, et al. Externalized Stents for Pancreatoduodenectomy Provide Value Only in High-Risk Scenarios. J Gastrointest Surg 2016;20:2052-62.

71. Lillemoe KD, Cameron JL, Kim MP, et al. Does fibrin glue sealant decrease the rate of pancreatic fistula after pancreaticoduodenectomy? Results of a prospective randomized trial. J Gastrointest Surg 2004;8:766-72; discussion 72-4.

72. Vakalopoulos KA, Daams F, Wu Z, et al. Tissue adhesives in gastrointestinal anastomosis: a systematic review. J Surg

\section{doi: $10.21037 / \operatorname{tgh} .2017 .11 .02$}

Cite this article as: Barreto SG, Shukla PJ. Different types of pancreatico-enteric anastomosis. Transl Gastroenterol Hepatol 2017;2:89.
Res 2013;180:290-300.

73. Cheng Y, Ye M, Xiong X, et al. Fibrin sealants for the prevention of postoperative pancreatic fistula following pancreatic surgery. Cochrane Database Syst Rev 2016;2:CD009621.

74. Ramia JM, de la Plaza R, Adel F, et al. Wrapping in pancreatic surgery: a systematic review. ANZ J Surg 2014;84:921-4.

75. McMillan MT, Soi S, Asbun HJ, et al. Risk-adjusted Outcomes of Clinically Relevant Pancreatic Fistula Following Pancreatoduodenectomy: A Model for Performance Evaluation. Ann Surg 2016;264:344-52. 